\title{
Light-induced olefin metathesis
}

\author{
Yuval Vidavsky and N. Gabriel Lemcoff
}

\section{Review}

\section{Address:}

Chemistry Department, Ben-Gurion University of the Negev,

Beer-Sheva 84105, Israel

Email:

N. Gabriel Lemcoff* - lemcoff@bgu.ac.il

* Corresponding author

Keywords:

catalysis; light activation; olefin metathesis; photoactivation;

photoinitiation; photoisomerisation; RCM; ROMP; ruthenium; tungsten
Beilstein J. Org. Chem. 2010, 6, 1106-1119.

doi:10.3762/bjoc.6.127

Received: 29 August 2010

Accepted: 14 October 2010

Published: 23 November 2010

Guest Editor: K. Grela

(C) 2010 Vidavsky and Lemcoff; licensee Beilstein-Institut. License and terms: see end of document.

\begin{abstract}
Light activation is a most desirable property for catalysis control. Among the many catalytic processes that may be activated by light, olefin metathesis stands out as both academically motivating and practically useful. Starting from early tungsten heterogeneous photoinitiated metathesis, up to modern ruthenium methods based on complex photoisomerisation or indirect photoactivation, this survey of the relevant literature summarises past and present developments in the use of light to expedite olefin ringclosing, ring-opening polymerisation and cross-metathesis reactions.
\end{abstract}

\section{Introduction}

The metal catalysed olefin metathesis reaction [1-8] has undoubtedly become one of the most widely used methodologies for the formation of carbon-carbon bonds. Its ubiquitous use in polymer chemistry [9-13] and natural product [1417] and fine chemical synthesis [3,18-20], ultimately led to the 2005 Nobel Prize award to Yves Chauvin, Richard Schrock and Robert Grubbs [21] for the development of this reaction. Since, olefin metathesis has seen much progress, such as the use of new ligands for aqueous applications [22-26], asymmetric synthesis [27-30] and latent catalysis [31]. Among the methods used to activate latent olefin metathesis catalysts we find, chemical methods [32] and physical methods; such as the use of thermal energy [33], mechanochemical energy [34] and, perhaps more conveniently, the use of light [35]. In this review we summarise the early beginnings of light induced olefin metathesis by the use of ill defined tungsten complexes, up to the most recent developments in light induced ruthenium based isomerisation and activation.

\section{Review}

\section{Early tungsten catalysed photometathesis}

The first examples for photoinitiated metathesis were published independently by Dubois and McNelis in 1975 using simple tungsten hexacarbonyl as the metal initiator in carbon tetra- 
chloride solvent [36,37]. This straightforward, cocatalyst free technique encouraged many research groups to investigate and develop this system.

Dubois demonstrated the photoinduced metathesis $(335 \mathrm{~nm})$ of trans-2-pentene to 2-butene and 3-hexene in 50\% conversion; while McNelis used a $254 \mathrm{~nm}$ Rayonet reactor for the metathesis of hept-3-ene, pent-2-ene, and E,E-deca-2,8-diene (Scheme 1).

$$
\curvearrowright \stackrel{\mathrm{W}(\mathrm{CO})_{6} \backslash \mathrm{CCl}_{4} \backslash \mathrm{hv}}{\longrightarrow}>\mathrm{m}_{2}+\mathrm{Cm}_{\mathrm{n}} /
$$

Scheme 1: Light activated metathesis of trans-2-pentene.

In the Dubois paper, when either light or carbon tetrachloride was excluded, no reaction could be observed. Furthermore, this research led to the proposal of the controversial mechanism shown in Scheme 2, which includes the generation of phosgene and the proposed active species, chloropentacarbonyl tungsten (2).

Alternatively, McNelis proposed that the active species was actually dichlorotetracarbonyl tungsten and demonstrated that phosgene was not generated by illumination of $\mathbf{1}$ when oxygen was excluded [38].

Following these first communications, Krausz, Garnier and Dubois published a series of papers investigating the photoinduced olefin metathesis with complex 1 [39-42]. Their main conclusions were:

$a: \mathrm{W}(\mathrm{CO})_{5}$ and $\mathrm{CO}$ are created by photolysis of $\mathrm{W}(\mathrm{CO})_{6}$. The reactivity of $\mathrm{W}(\mathrm{CO})_{5}$ was found to be solvent dependent.

$b$ : The intensity of irradiation, and the concentrations of both olefin and catalyst had a significant effect on reaction yields.

c: The $\mathrm{RCH}=\mathrm{CCl}_{2}$ produced in the reaction was a result of a reaction between a tungsten dichlorocarbene species and the double bond.
Research on the photo-activation of $\mathrm{W}(\mathrm{CO})_{6}$ was further expanded by Harfouch et al. [43,44], Matsuda et al. [45], Szymańska-Buzar and Ziółkowski [46,47] and Zümreoglu [48], and was first reviewed in 1988 by Szymańska-Buzar [49]. The main conclusions from this wave of research dealt with the mechanistic role of the halide additives, as well as diverse reaction conditions, such as the use of other metals (i.e., $\mathrm{Cr}$ and Mo) that usually led to addition type reactions instead of metathesis.

In later work, Mol et al. [50] determined the heterogeneous character of the active catalytic species obtained on irradiation of $\mathbf{1}$ in $\mathrm{CCl}_{4}$, supporting the previous proposal by Harfouch and coworkers. In another example of heterogeneous light induced metathesis, Shelimov and Kazansky [51] also found that silica supported molybdenum trioxide $\left(\mathrm{MoO}_{3} / \mathrm{SiO}_{2}\right)$ could be activated by UV irradiation under an alkane atmosphere in the metathesis of propene and 1-hexene.

More recently, Sundararajan et al. [52-54], and Higashimura et al. [55] applied $\mathrm{W}(\mathrm{CO})_{6} / \mathrm{CX}_{4} / \mathrm{h} v$ methodologies for the polymerisation of alkyne derivatives, especially phenylacetylene. These works were based on earlier observations by Katz et al. [56,57] and Geoffrey et al. [58] that acetylenes irradiated in the presence of tungsten complexes form metal carbenes that can produce polymeric species.

\section{Well-defined tungsten catalysed photometathesis}

The first example of well-defined early transition metal complexes for photocatalysed ROMP (PROMP) 3 and $\mathbf{4}$ (Figure 1) was published by van der Schaaf, Hafner, and Mühlebach [59].

Complexes $\mathbf{3}$ and $\mathbf{4}$ displayed reasonable thermal stability in solution (no decomposition was observed after $1 \mathrm{~d}$ at $80{ }^{\circ} \mathrm{C}$ ), but were moisture sensitive and had to be handled under an inert atmosphere. Complex $\mathbf{3}$ slowly polymerised dicyclopentadiene (DCPD) in the dark at $60^{\circ} \mathrm{C}$, in contrast, when exposed to light even at room temperature, polymerisation was rapid and complete after $15 \mathrm{~min}$. Enhanced behaviour was observed with complex 4, which boasted true latency [60] and did not show

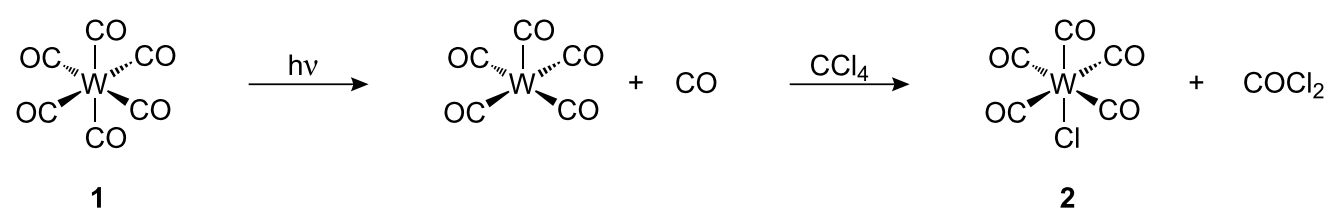




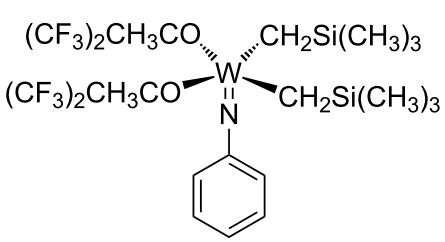

3

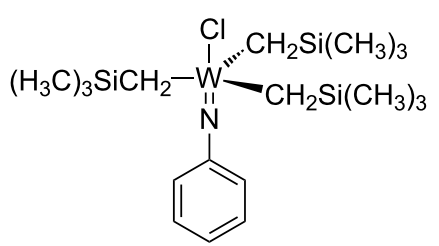

4

Figure 1: Well-defined tungsten photoactive catalysts.

any polymerisation of DCPD at $80^{\circ} \mathrm{C}$. Whilst a solution of 4 and DCPD can stand for days with no apparent polymerisation, irradiation with UV light led to fast polymerisation.

\section{Ruthenium catalysed photometathesis}

The first example for PROMP using ruthenium initiators was disclosed by Mühlebach et al. in 1995 [61]. Three main types of ruthenium-based precatalysts: $\eta^{6}$-arene sandwich complexes, half-sandwich complexes and nitrile complexes (Figure 2) were shown to promote the polymerisation of strained cyclic alkenes (Figure 3) when irradiated by UV light.

Advantageously, the systems showed none to moderate activity for normal ROMP, and were not sensitive to oxygen and humidity compared to the tungsten initiators described above. Notably, heating the sandwich catalysts for more than $24 \mathrm{~h}$ at $50{ }^{\circ} \mathrm{C}$ in the presence of the monomers did not induce polymerisation, on the other hand, the nitrile complexes displayed low

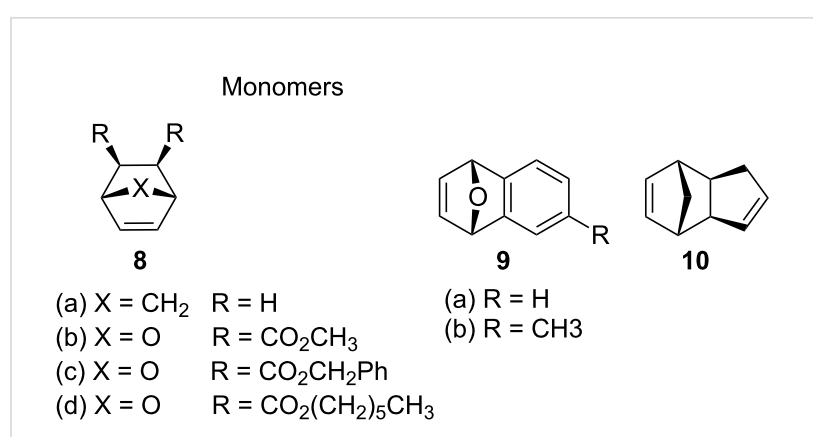

Figure 3: Cyclic strained alkenes for PROMP.

activity even at room temperature. UV irradiation at $364 \mathrm{~nm}$ significantly enhanced the activity of all these complexes. The activity of the compounds, including comparisons with thermally active catalysts, are summarised in Table 1.

Overall, the polymers obtained from norbornene and oxanorbornene derivatives had high molecular weights $\left(M_{\mathrm{w}}>\right.$ $150 \mathrm{kDa})$ and also high monomodal polydispersities $\left(M_{\mathrm{W}} / M_{\mathrm{n}}>\right.$ 2.3). Polymerisation was also found to occur if the monomer was added after irradiation of the complex. In addition, the initial rate of polymerisation was found to be linearly dependent on the irradiation time. Conversely, irradiation above $420 \mathrm{~nm}$ did not initiate polymerisation for most of the complexes investigated.

As in most systems of this type, activation of the precatalyst is dependent on the photochemically induced cleavage of a metal-ligand bond which leads to the active species. The mechanism for initiation of the sandwich compounds was proposed to proceed through gradual photodissociation of the arene ligand, followed by solvation of the photochemically excited molecule (Scheme 3).
Sandwich and halfsandwich complexes

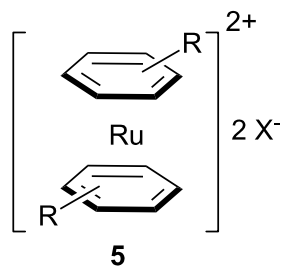

$R$

$=(\mathrm{a})$ benzene, $(\mathrm{b})$ toluene,

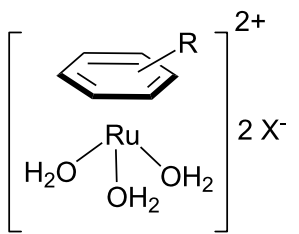

6

Nitrile complexes<smiles>[R]N[R](N=[R])(N=[R])([N+]#[R])NCC</smiles>

7<smiles></smiles>

(trif)<smiles>Cc1ccc(S(=O)(=O)[O-])cc1</smiles>

(tos)

(c) mesitylene, (d) hexamethyl-

benzene, (e) anisole, (f) biphenyl,

(g) naphthalene

$\mathrm{R}=(\mathrm{a}) \mathrm{CH}_{3}$, (b) $\mathrm{CH}_{2} \mathrm{CH}_{3}$, (c) $\mathrm{Ph}$

Figure 2: The first ruthenium based complexes for PROMP 
Table 1: Activation of ruthenium complexes with and without irradiation ${ }^{a}$

$\begin{array}{lll}\text { Entry Compound } & \text { Catalytic activity }\end{array}$

$h v^{b}$

1

2

Half-sandwich complexes

3

4

5

6

Sandwich complexes

7

8

9

10

11

12

13

14

15

16

17

18

19

20

21

\section{Nitrile complexes}

22

23

24

25

26

27

\section{$\left[\mathrm{Ru}\left(\mathrm{H}_{2} \mathrm{O}\right)_{6}\right](\text { tos })_{2}$}

$\left[\mathrm{Ru}\left(\mathrm{H}_{2} \mathrm{O}\right)_{6}\right]$ (trif)

$\left[\left(\mathrm{C}_{6} \mathrm{H}_{6}\right) \mathrm{Ru}\left(\mathrm{H}_{2} \mathrm{O}\right)_{3}\right]$ (tos $)_{2}$

[(toluene) $\left.\mathrm{Ru}\left(\mathrm{H}_{2} \mathrm{O}\right)_{3}\right]$ (tos) 2

[(hexamethylbenzene) $\mathrm{Ru}\left(\mathrm{H}_{2} \mathrm{O}\right)_{3}$ ] (tos $)_{2}$

$\left[\left(\mathrm{C}_{6} \mathrm{H}_{6}\right) \mathrm{Ru}(\text { acetonitrile })_{3}\right]$ (tos $)_{2}$

$\left[\left(\mathrm{C}_{6} \mathrm{H}_{6}\right)_{2} \mathrm{Ru}\right](\text { tos })_{2}$

$\left[\left(\mathrm{C}_{6} \mathrm{H}_{6}\right) \mathrm{Ru}\right.$ (toluene) $]$ (tos) $)_{2}$

$\left[\left(\mathrm{C}_{6} \mathrm{H}_{6}\right) \mathrm{Ru}\right.$ (mesitylene)](tos) 2

$\left[\left(\mathrm{C}_{6} \mathrm{H}_{6}\right) \mathrm{Ru}\right.$ (hexamethylbenzene)](tos) 2

[(mesitylene)Ru(hexamethylbenzene)] $\left(\mathrm{BF}_{4}\right)_{2}$

[(hexamethylbenzene) $)_{2} \mathrm{Ru}$ ](tos) 2

$\left[\left(\mathrm{C}_{6} \mathrm{H}_{6}\right) \mathrm{Ru}\right.$ (anisole)](tos) 2

$\left[\left(\mathrm{C}_{6} \mathrm{H}_{6}\right) \mathrm{Ru}\right.$ (biphenyl)](tos) 2

$\left[\left(\mathrm{C}_{6} \mathrm{H}_{6}\right) \mathrm{Ru}\right.$ (naphthalene) $](\text { tos })_{2}$

$\left[\left(\mathrm{C}_{6} \mathrm{H}_{6}\right) \mathrm{Ru}\right.$ (chrysene) $]$ (tos) ${ }_{2}$

$\left[\left(\mathrm{C}_{6} \mathrm{H}_{6}\right) \mathrm{Ru}\right.$ (tetramethylthiophene $\left.)\right](\text { tos })_{2}$

$\left[\left(\mathrm{C}_{6} \mathrm{H}_{6}\right) \mathrm{Ru} \text { (triphos)](tos }\right)_{2}$

$\left[\left(\mathrm{C}_{6} \mathrm{H}_{6}\right) \mathrm{Ru}\left(1,2,4-\mathrm{C}_{6} \mathrm{H}_{3} \mathrm{Me}_{3}\right)\right]\left(\mathrm{BF}_{4}\right)_{2}$

$\left[\left(\mathrm{C}_{6} \mathrm{H}_{6}\right) \mathrm{Ru}\left(1 R, 2 \mathrm{~S}\right.\right.$-trans- $\left.\left.\mathrm{C}_{12} \mathrm{H}_{16} \mathrm{O}\right)\right]\left(\mathrm{BF}_{4}\right)_{2}$

$\left[\left(\mathrm{C}_{6} \mathrm{H}_{6}\right) \mathrm{Ru}\left(1 \mathrm{~S}, 2 \mathrm{R}\right.\right.$-trans- $\left.\left.-\mathrm{C}_{12} \mathrm{H}_{16} \mathrm{O}\right)\right]\left(\mathrm{BF}_{4}\right)_{2}$

[Ru(acetonitrile) $\left.)_{6}\right](\text { tos })_{2}$

[Ru(acetonitrile) $\left.)_{6}\right]$ (trif) 2

[Ru(propionitrile $\left.)_{6}\right]$ (tos $)_{2}$

[Ru(propionitrile $\left.)_{6}\right](\text { trif })_{2}$

[Ru(benzonitrile) $\left.)_{6}\right]$ (tos) 2

[Ru(benzonitrile $\left.)_{6}\right](\text { trif })_{2}$
Very high

Very high

Medium

Weak

Very weak

Medium

None

None

None

None

None

None

Weak

None

Medium

Medium

None

None

None

None

None

Weak

Weak

Weak

Weak

Weak

Weak
High

Medium

Very weak

High

Medium

Weak

Weak

Weak

Very weak

High

Very high

Very high

Very high

Very high

None

Weak

Weak

weak

High

High

High

High

Medium

Medium

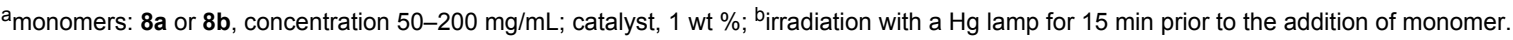

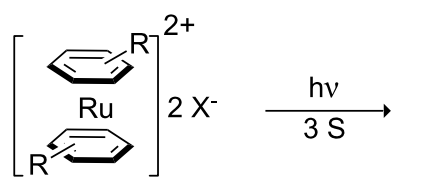

5
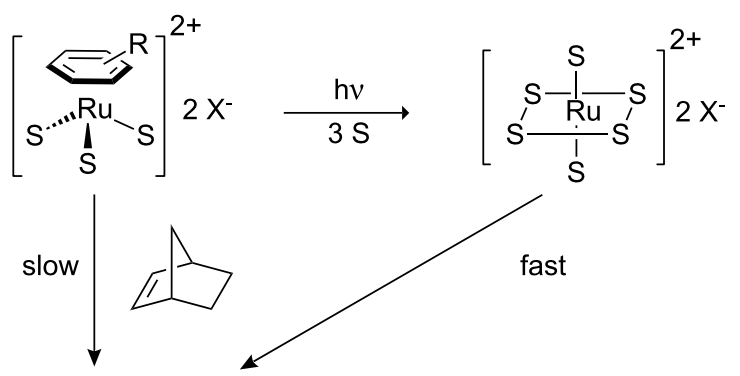<smiles>C=C(C)C1CCC(C(C)C)C1</smiles>

$\mathrm{S}=$ solvent 
Both the intermediate half-sandwich species $\left[\left(\eta^{6}-\right.\right.$ arene) $\left.\mathrm{Ru}(\text { solvent })_{3}\right]^{2+}$ and the fully solvated complex $\left[\mathrm{Ru}(\text { solvent })_{6}\right]^{2+}$ are thermally active ROMP catalysts for strained bicyclic olefins, the latter being the more active. Thus, Mühlebach concluded that PROMP results mainly from the phototransformation of the sandwich complex to the fully solvated complex. The nitrile complexes are proposed to be activated by a similar mechanism where several species of the type $\left[\mathrm{Ru}(\mathrm{RCN})_{6-\mathrm{x}}\left(\mathrm{H}_{2} \mathrm{O}\right)_{\mathrm{x}}\right]$ are responsible for the polymerisation initiation.

Disadvantages of these catalysts are the overall moderate activities achieved and that they are only soluble in polar solvents, due to their cationic character. On the other hand, the complexes are readily available and the use of aqueous solvents as the reaction media can also be envisaged as an attractive feature.

Mühlebach, Hafner and van der Schaaf [62] carried on the development of ruthenium and osmium photoactivated catalysts (Figure 4) by adding a bulky phosphane ligand to the complex. Thus, a more active and soluble neutral species with the anionic ligands bound to the metal could be obtained. The same concept of arene displacement by UV radiation was used for the release of a $p$-cymene ligand to produce a more reactive catalytic species.

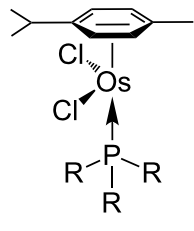

11

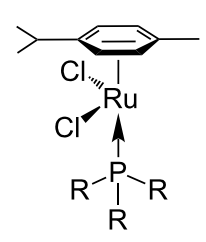

12
$\mathrm{R}=(\mathrm{a}) n$-butyl, (b) isopropyl, (c) cyclohexyl, (d) phenyl, (e) methyl, (f) $m$-tolyl

$\mathrm{R}=(\mathrm{a}) n$-butyl, (b) cyclohexyl, (c) $m$-tolyl

Figure 4: Ruthenium and osmium complexes with $p$-cymene and phosphane ligands for PROMP.

Osmium precatalysts 11a-f did not polymerise norbornene under standard conditions. However, 5 min irradiation of a toluene solution of the complex with a $200 \mathrm{~W} \mathrm{Hg}$ lamp led to active catalysts. The more active catalysts were those possessing more sterically hindered phosphane ligands. Thus, complexes with larger cone angles $\theta$, such as $\mathbf{1 1 b}\left(\theta=160^{\circ}\right)$ and 11c $\left(\theta=170^{\circ}\right)$ showed strong metathetic activity for PROMP of norbornene and dicylopentadiene in toluene solution or even in aqueous dispersions; by contrast, complexes $11 \mathbf{a}, \mathbf{d}, \mathbf{e}, \mathbf{f}\left(\theta=130^{\circ}, 145^{\circ}, 120^{\circ}, 150^{\circ}\right)$ showed slow no reaction even after UV irradiation. The ruthenium complexes $\mathbf{1 2}$ showed much higher reactivity in the polymerisation of norbornene, albeit none of these complexes was completely thermally latent for this reaction. The remarkable tolerance of $\mathbf{1 2 b}$ to impurities and water, was highlighted by the fact that polymerisation can take place in water dispersions containing fillers such as $\mathrm{SiO}_{2}$, $\mathrm{AI}(\mathrm{OH})_{3}$, or $\mathrm{CaCO}_{3}$ up to a loading of $70 \mathrm{wt} \%$. The electrical and mechanical properties of PDCPD were preserved, making this system highly interesting for novel applications. The work of Mühlebach, Hafner and van der Schaaf on photoinduced ring-opening metathesis polymerisation was reviewed in 1997 [63].

The interest in photoactivated olefin metathesis motivated Fürstner [64] to use complex 12b for photoinduced ring closing metathesis (RCM) by using regular neon light or strong daylight as a photon source instead of the UV lamps used thus far. Indeed, 12b catalysed the ring-closing metathesis reaction of diallyl tosylamide in $90 \%$ yield when illuminated by neon light. Alternatively, the commercially available dimer complex $\mathbf{1 3}$ (Figure 5) mixed with $\mathrm{PCy}_{3}$ could be irradiated to produce similar results.

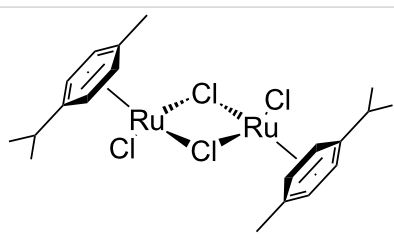

13

Figure 5: Commercially available photoactive ruthenium precatalyst.

Some of the photoinduced RCM products obtained by neon light irradiation of dimer $\mathbf{1 3}$ are highlighted in Figure 6. Perhaps the main benefit of this procedure lies in its simplicity since it only requires commercially available metal complexes and commonly used lighting equipment.

An additional expansion to photopromoted RCM was described in 1998 by Dixneuf et al. [65], who used the cationic allenylidene ruthenium complex 14 (Scheme 4) for the ene-yne RCM of propargylic allyl ethers into 3-vinyl-2,5-dihydrofurans.

The best conditions reported for this reaction were the irradiation of a toluene solution of $\mathbf{1 4}$ and substrate with an Hg lamp at $300 \mathrm{~nm}$ for $30 \mathrm{~min}$ at room temperature, followed by heating at $80{ }^{\circ} \mathrm{C}$ until completion of the reaction. The reaction time, compared to the non-irradiated control experiment, was reduced six fold. The various dihydrofuran rings obtained by this method are shown in Figure 7 along with their respective yields and the required reaction times. 


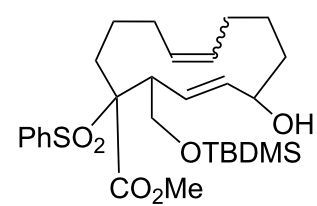

$68 \%$

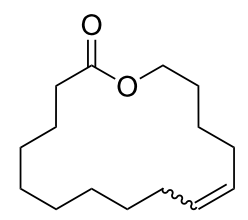

$80 \%$<smiles>COCC/C=C\CC1C(=O)CC[C@H]1CC(=O)OC</smiles>

$65 \%$

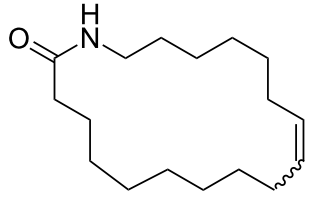

$75 \%$

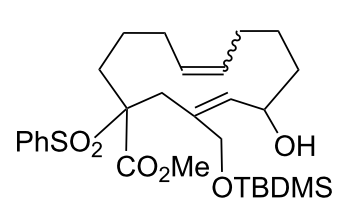

$70 \%$

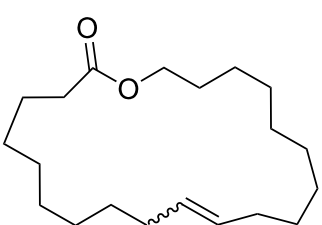

$72 \%$

Figure 6: Some of the rings produced by photo-RCM

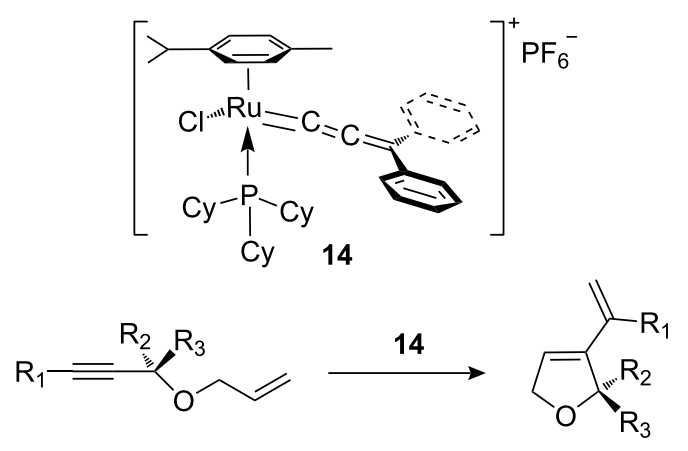

Scheme 4: Photopromoted ene-yne RCM by cationic allenylidene ruthenium complex 14 .

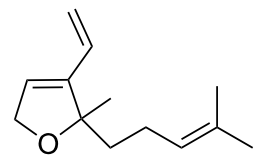

$1 \mathrm{~h}, 74 \%$

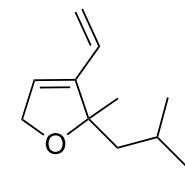

$1 \mathrm{~h}, 62 \%$

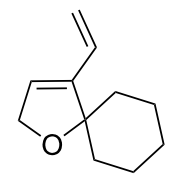

$1 \mathrm{~h}, 63 \%$

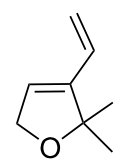

$63 h^{a}, 41 \%$<smiles>C=C(C)C1=CCOC1(C)c1ccccc1</smiles>

$24 \mathrm{~h}, 83 \%$<smiles>C=CC1=CCOC1(c1ccccc1)c1ccccc1</smiles>

$23 \mathrm{~h}, 67 \%$

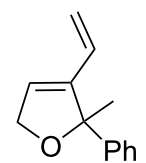

$4 \mathrm{~h}, 84 \%$
aRefluxing $\mathrm{CH}_{2} \mathrm{Cl}_{2}$ instead of toluene at $80{ }^{\circ} \mathrm{C}$.

Figure 7: Dihydrofurans synthesised by photopromoted ene-yne RCM

In line with the development of ruthenium benzylidene initiators $[66,67]$, the phosphane ligand was replaced by an $N$-heterocyclic carbene (NHCs) in the photoactivated precatalysts. Accordingly, Noels et al. [68,69] synthesised a range of NHC substituted ruthenium cymene complexes (Figure 8) either by replacing the phosphane ligand in complex $\mathbf{1 2}$ by NHC ligands or via direct synthesis from 13. Complexes $\mathbf{1 5}$ and $\mathbf{1 6}$ were tested as photoactivated ROMP catalysts. In all cases cyclooctene was used as a standard cyclic olefin monomer for the polymerisation studies.

Illuminating 15 or 16 with intense visible light, or even with regular laboratory lighting, revealed a dramatic improvement in their ROMP activity. Results of PROMP by complex 16g (Mes ligand) and cyclooctene are summarised in Table 2. The large difference in polymer molecular weight between the dark and light reactions was not explained, even though it is slightly counterintuitive.

In order to improve the understanding of the photoactivation mechanism, complex 16g was irradiated by visible light both in the presence and absence of cyclooctene. NMR and UV spectra confirmed the release of $p$-cymene from the complex in the photochemical process; however, the active species and overall mechanism were not elucidated. Both saturated and unsaturated NHC ligands afforded similar results. However, blocking both ortho positions on the aromatic groups of the NHCs was crucial for the performance of the catalyst.

The ruthenium photoactivated catalytic systems described so far possessed noticeable ROMP activity at temperatures higher than room temperature even without being exposed to light; especially with the more reactive monomers such as norbornene and dicyclopentadiene. Buchmeiser argued that in order to integrate light activated precatalyst in practical applications, latency must be significant also at higher temperatures. Therefore, Buchmeiser et al. concentrated efforts towards the design of 'true' latent photoactivated ruthenium precatalysts for 


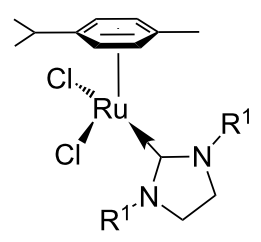

15

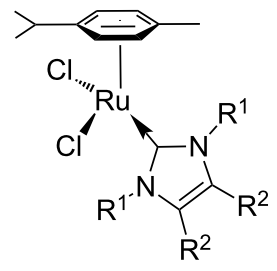

16
(a) $R^{1}=$ Dipp
(e) $R^{1}=d m p h$
(b) $R^{1}=$ Mes
(f) $R^{1}=$ biph
(c) $\mathrm{R}^{1}=\mathrm{Ph}$
(g) $R^{1}=2$-tolyl
(d) $R^{1}=$ Naph
(h) $R^{1}=x y l y l$
Cy $=$ cyclohexyl
Dipp $=2,6$-diisopropylphenyl
Mes $=2,4,6$-trimethylphenyl
$\mathrm{dmph}=3,5$-dimethylphenyl
biph $=4$-biphenyl
2-tolyl = 2-methylphenyl
xylyl = 2,6-dimethylphenyl

(a) $R^{1}=R^{2}=M e$
(b) $R^{1}=i \operatorname{Pr}, R^{2}=H$
(c) $R^{1}=\operatorname{Pr}, R^{2}=M e$
(d) $R^{1}=\mathrm{Cy}, R^{2}=H$
(e) $R^{1}=\mathrm{Cy}, R^{2}=\mathrm{Me}$

(f) $\mathrm{R}^{1}=\mathrm{Dipp}, \mathrm{R}^{2}=\mathrm{H}$

(k) $\mathrm{R}^{1}=$ Naph, $\mathrm{R}^{2}=\mathrm{H}$

(g) $\mathrm{R}^{1}=$ Mes, $\mathrm{R}^{2}=\mathrm{H}$

(l) $\mathrm{R}^{1}=\mathrm{dmph}, \mathrm{R}^{2}=\mathrm{H}$

(h) $R^{1}=$ Mes, $R^{2}=M e$

(m) $\mathrm{R}^{1}=$ biph, $\mathrm{R}^{2}=\mathrm{H}$

(i) $\mathrm{R}^{1}=$ Mes, $\mathrm{R}^{2}=\mathrm{Cl}$

(n) $\mathrm{R}^{1}=$ 2-tolyl, $\mathrm{R}^{2}=\mathrm{H}$

(j) $R^{1}=P h, R^{2}=H$

(o) $R^{1}=x y l y l, R^{2}=H$

Figure 8: Ruthenium complexes with p-cymene and NHC ligands.

Table 2: Effect of light on the ROMP of cyclooctene using $16 \mathrm{~g}$ as catalyst.

\begin{tabular}{cccc}
$\begin{array}{c}\text { Lighting } \\
\text { conditions }\end{array}$ & $\begin{array}{c}\text { Monomer } \\
\text { conversion (\%) }\end{array}$ & $\begin{array}{c}\text { Isolated } \\
\text { yield (\%) }\end{array}$ & $\begin{array}{c}M_{\mathrm{n}} \\
\left(\times 10^{3} \mathrm{~g}\right)\end{array}$ \\
\hline Darkness & 20 & 20 & 21 \\
Normal $^{\mathrm{a}}$ & 93 & 84 & 625 \\
Neon tube $^{\mathrm{b}}$ & 99 & 93 & 553 \\
Light bulb $^{\mathrm{c}}$ & $>99$ & 91 & 537 \\
\hline
\end{tabular}

anormal lighting, a combination of daylight and fluorescent light; bordinary $40 \mathrm{~W}$ 'cold white' fluorescent tube, $10 \mathrm{~cm}$ away from the standard Pyrex reaction flask; ${ }^{c} 250 \mathrm{~W}$ incandescent light bulb, $10 \mathrm{~cm}$ away from the standard Pyrex reaction flask.

ROMP [70]. These precatalysts, similar to Noels' complexes, included NHCs, and in some cases the $p$-cymene ligand was exchanged for phenylisonitrile and in others the chloride ligands were replaced by trifluroacetate. These transformations were expected to generate more stable, inert, precatalysts that would require external triggers to initiate the dissociation of the neutral ligand to produce the active species.

Complexes 17-20 (Scheme 5) initiated ROMP of norborn-5ene-2-ylmethanol 21 only at temperatures over $40{ }^{\circ} \mathrm{C}$ or by illumination at $172 \mathrm{~nm}$. However, the reaction conditions required the removal of oxygen from the system, an encumbrance in practical applications. In addition, more reactive monomers, such as 2-norbornene, were thermally polymerised by the complexes even at room temperature.
In 2008 Buchmeiser introduced the improved cationic latent phototriggered precatalysts 22 and $\mathbf{2 3}$ (Figure 9) [71]. These cationic species were inactive at higher temperatures $(\mathrm{T}<$ $45^{\circ} \mathrm{C}$ ) and did not thermally initiate the polymerisation of several ROMP monomers, including the highly reactive dicyclopentadiene 25 (DCPD) (Figure 10).

Irradiation at $308 \mathrm{~nm}$ of complex $\mathbf{2 2}$ or $\mathbf{2 3}$ in chloroform in the presence of the monomers resulted in polymerisations with 5-99\% conversion yields (Table 3). On changing the light source to a $254 \mathrm{~nm} \mathrm{Hg}$ lamp improved the yields to $70-99 \%$ (Table 3).

The proposed mechanism for the photoactivation of precatalysts 22 and 23 is displayed in Scheme 6.

Three additional new complexes for PROMP were recently published by Buchmeiser et al. [72] Although the complexes

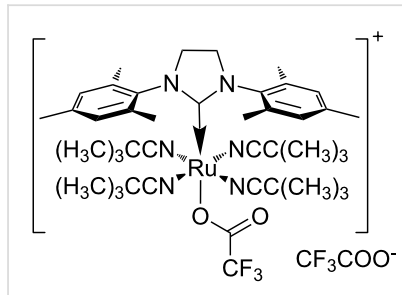

22

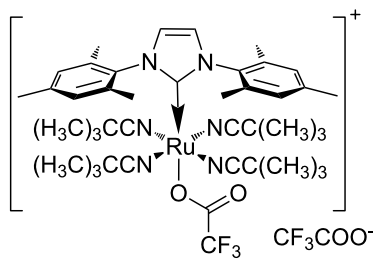

23
Figure 9: Photoactivated cationic ROMP precatalysts. 

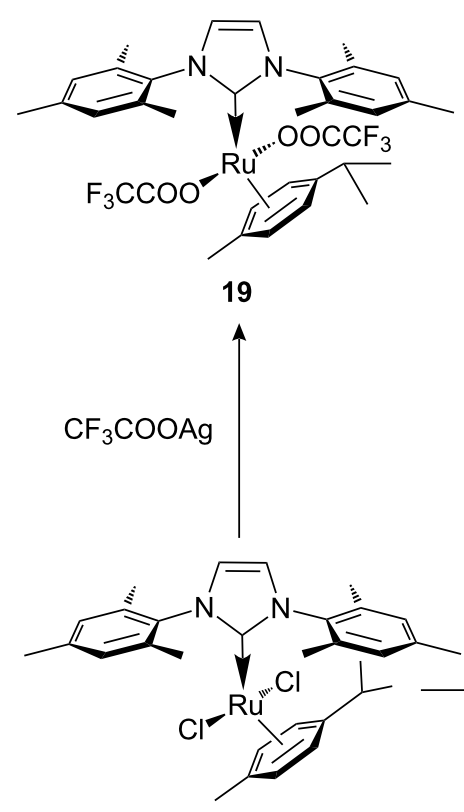

$16 \mathrm{~g}$

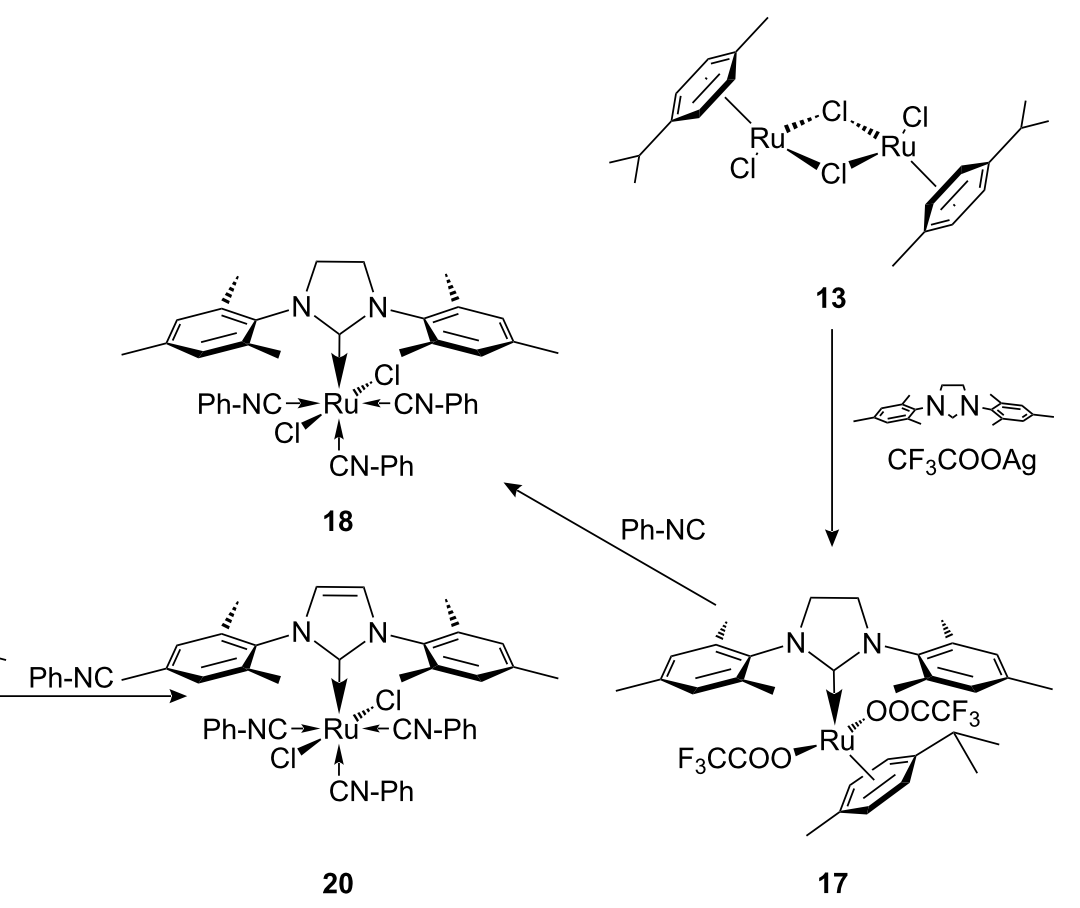

20<smiles>CCOC(=O)C1C2C=CC(C2)C1C(=O)N1C(=O)C2CCC1C2</smiles>

26

27

28

29

Figure 10: Different monomers for PROMP.

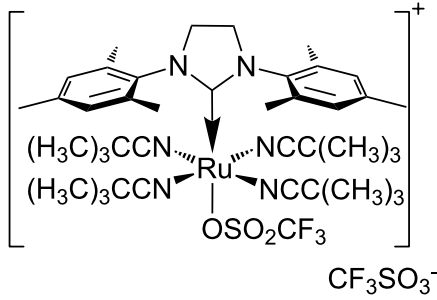

30

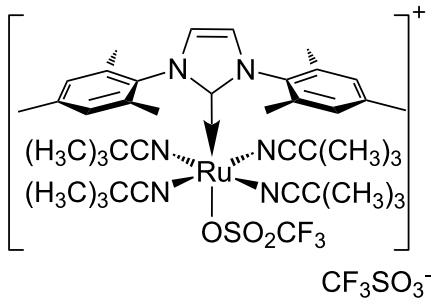

31
30-32 (Figure 11) are not true latent precatalysts, only minor polymerisation occurred in the absence light $(<5 \%$ at room temperature after $24 \mathrm{~h}$ ). However, when the monomer-complex mixture was irradiated with a $254 \mathrm{~nm}$ UV source, polymerisation occurred with more than $60 \%$ conversion within $1 \mathrm{~h}$ in most cases.

A desirable enhancement in phototriggered catalysis is the generation of photoswitchable systems. Thus, a specific reaction may be turned on by one type of stimulus (heat, light), and turned off by another. We have recently developed latent sulfur chelated Hoveyda-Grubbs type complexes (Figure 12), as thermo-switchable catalysts for RCM and ROMP [73-77].

Figure 11: Light-induced cationic catalysts for ROMP. 


\begin{tabular}{|c|c|c|c|c|}
\hline \multirow[t]{2}{*}{ Catalyst } & \multirow[t]{2}{*}{ Monomer } & \multicolumn{2}{|c|}{ Yield $^{b}$} & \multirow[t]{2}{*}{$M_{\mathrm{n}}^{\mathrm{d}}$} \\
\hline & & $308 \mathrm{~nm}$ & $254 \mathrm{~nm}$ & \\
\hline 22 & 24 & $40^{c}$ & $95^{c}$ & $4.8 \times 10^{5}$ \\
\hline 22 & 25 & 82 & 99 & - \\
\hline 22 & 26 & 69 & 85 & $2.1 \times 10^{5}$ \\
\hline 22 & 27 & 90 & 92 & $8.8 \times 10^{5}$ \\
\hline 22 & 28 & $<5^{c}$ & 90 & $2.6 \times 10^{5}$ \\
\hline 22 & 29 & $33^{c}$ & $99^{c}$ & $4.0 \times 10^{5}$ \\
\hline 23 & 24 & $41^{c}$ & $92^{c}$ & - \\
\hline 23 & 25 & $>99$ & 99 & - \\
\hline 23 & 26 & 61 & 67 & $4.4 \times 10^{5}$ \\
\hline 23 & 27 & 91 & 90 & $8.8 \times 10^{5}$ \\
\hline 23 & 28 & $<5^{c}$ & 86 & $4.5 \times 10^{5}$ \\
\hline 23 & 29 & $21^{c}$ & $>99^{c}$ & $4.9 \times 10^{4}$ \\
\hline
\end{tabular}

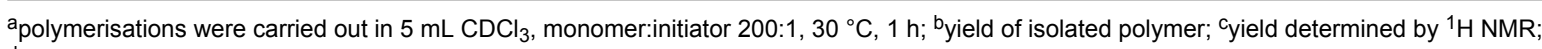
${ }^{d}$ molecular weights measured for the polymers obtained with $254 \mathrm{~nm}$ irradiation.

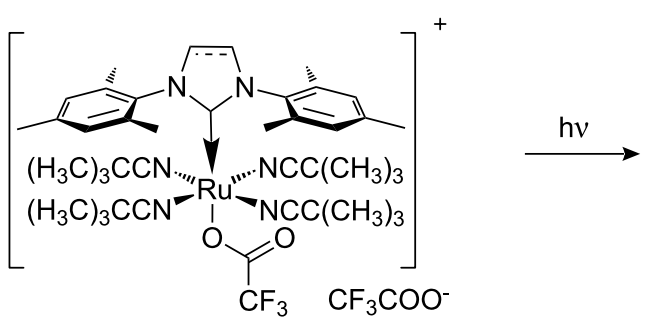

22 or 23
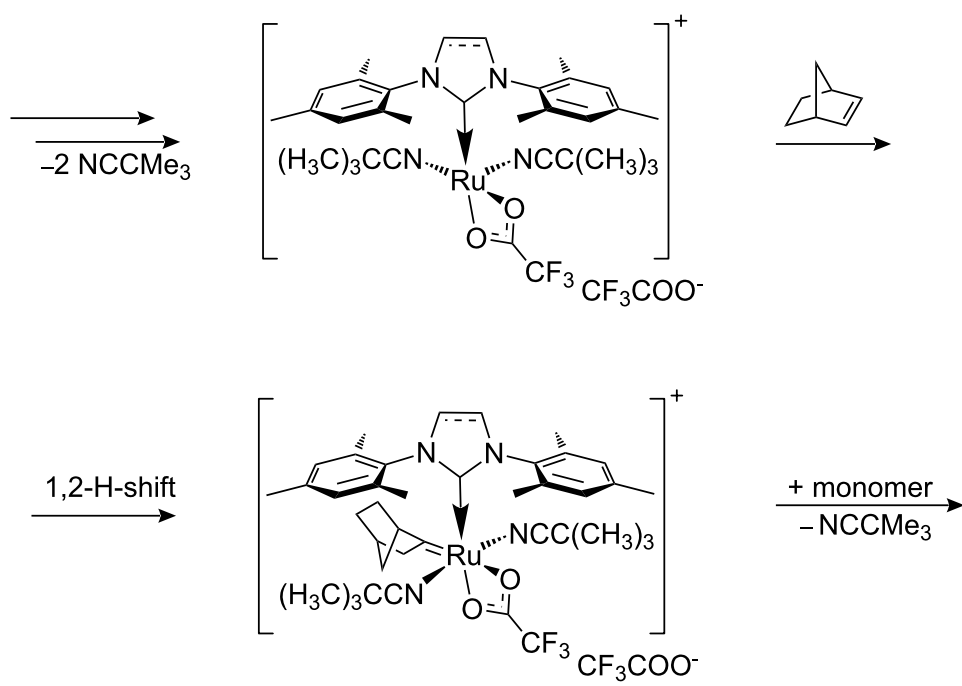

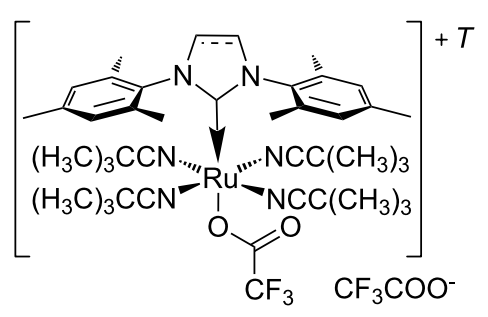

$22^{T}$ or $23^{T}$
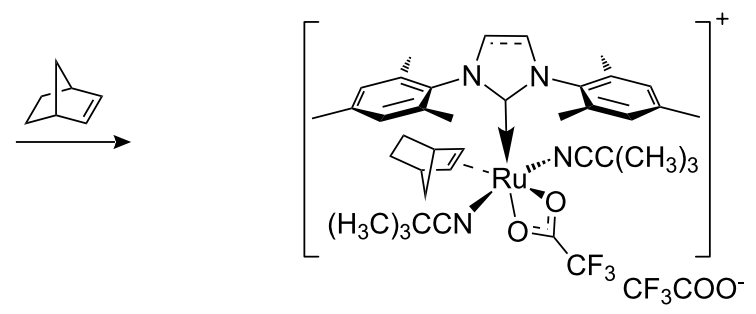

Polymer

Scheme 6: Proposed mechanism for photoinitiated polymerisation by 22 and 23 .

The thermal latency of the sulfur chelated complexes make them ideal candidates for photoswitchable applications; especially in light of the well documented photodissociation of ruthenium sulfur ligands.
Therefore, complexes 33a, e, f, $\mathbf{g}$ were irradiated at $365 \mathrm{~nm}$ in the presence of RCM and ROMP substrates [78]. A summary of the results is presented in Table 4 and Table 5. 


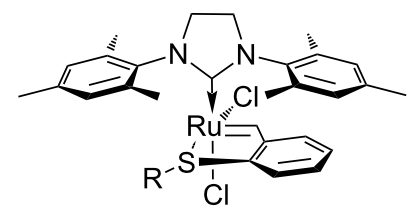

cis

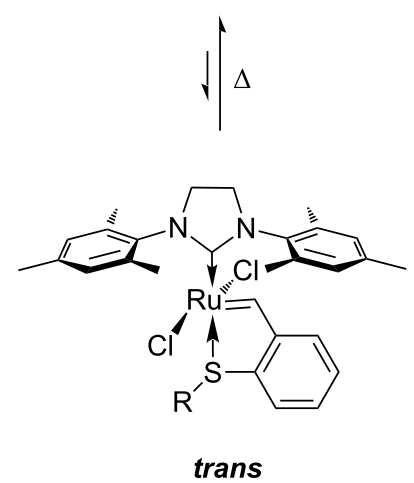

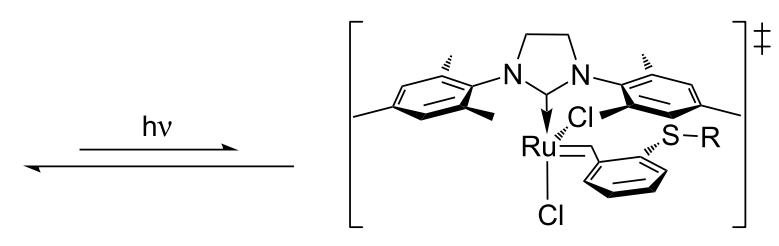

cis $-14 e^{-}$

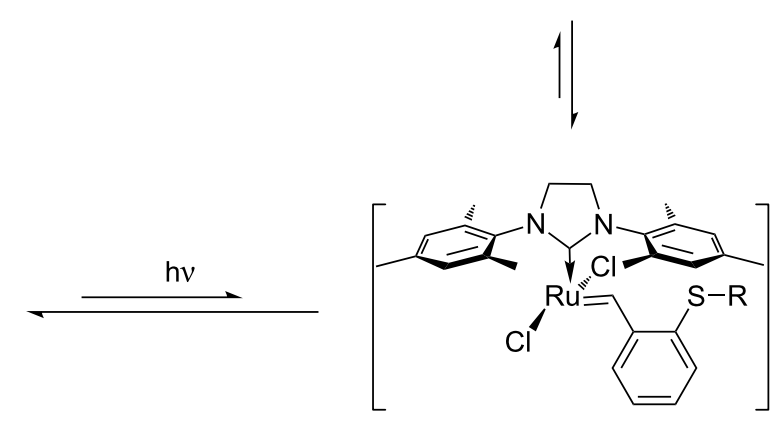

trans $-14 e^{-}$

Scheme 7: Proposed mechanism for the photoactivation of sulfur-chelated ruthenium benzylidene.

Table 4: Photo RCM of different substrates ${ }^{\mathrm{a}}$.

Catalyst

a mol\% catalyst, $0.1 \mathrm{M}$ substrate in $\mathrm{CH}_{2} \mathrm{Cl}_{2}$ at $28^{\circ} \mathrm{C} ; 365 \mathrm{~nm} \mathrm{UV}$ irradiation for $5 \mathrm{~h}$; byields were determined by GC-MS after $24 \mathrm{~h}$; no reaction observed without UV irradiation; 'includes isomerisation products.

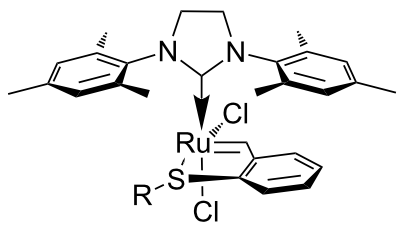

33

$\mathrm{R}=(\mathrm{a}){ }^{\mathrm{i}} \mathrm{Pr},(\mathrm{b}) \mathrm{Me},(\mathrm{c}) t-\mathrm{Bu},(\mathrm{d}) \mathrm{Et},(\mathrm{e}) \mathrm{Ph}$, (f) b-Naph, (g) 1-Pyr

Figure 12: Sulfur chelated ruthenium benzylidene pre-catalysts for olefin metathesis.

Table 5: PROMP with sulfur chelated complexes ${ }^{\mathrm{a}}$.

\begin{tabular}{|c|c|c|c|c|}
\hline Monomer & Catalyst & Conversion $^{b}$ & $\mathrm{PDI}^{\mathrm{C}}$ & $M_{\mathrm{n}}{ }^{\mathrm{C}}$ \\
\hline $\begin{array}{l}{ }_{2} \mathrm{Me} \\
\mathrm{Me}\end{array}$ & $\begin{array}{l}33 e \\
33 f\end{array}$ & $\begin{array}{l}40 \% \\
66 \%\end{array}$ & $\begin{array}{l}1.5 \\
1.5\end{array}$ & $\begin{array}{l}2.5 \times 10^{5} \\
2.5 \times 10^{5}\end{array}$ \\
\hline & $\begin{array}{l}33 e \\
33 f\end{array}$ & $\begin{array}{c}96 \% \\
>99 \%\end{array}$ & $\begin{array}{l}1.3 \\
1.2\end{array}$ & $\begin{array}{l}1.1 \times 10^{5} \\
1.3 \times 10^{5}\end{array}$ \\
\hline & $\begin{array}{l}33 e \\
33 f\end{array}$ & $\begin{array}{l}86 \% \\
84 \%\end{array}$ & $\begin{array}{l}1.4 \\
1.5\end{array}$ & $\begin{array}{l}5.0 \times 10^{4} \\
7.0 \times 10^{4}\end{array}$ \\
\hline
\end{tabular}

amonomer concentration $0.5 \mathrm{M}$ in $\mathrm{CH}_{2} \mathrm{Cl}_{2}$; [monomer]/[cat] = 300;

bconversions were determined by GC-MS after $24 \mathrm{~h}$ with mesitylene as internal standard; ${ }^{c} M_{\mathrm{n}}$ and PDI values were determined by GPC. 
The discovery that light irradiation induces photoisomerisation of the cis-dichloro complexes led to the proposed mechanism shown in Scheme 7. Thus, photoactivation of sulfur-chelated ruthenium benzylidene complexes was found to depend on the generation of the active trans-dichloro isomer via 14-electron intermediates.

The design of a photoswitchable system was based on the fact that the latent isomer (cis-dichloro) was thermodynamically more stable than its active counterpart (trans-dichloro). Thus, illumination with UV light generates an active isomer, but a short heating period regenerates the inactive isomer. The switchable nature of the system was demonstrated by $15 \mathrm{~min}$ irradiation of a tetrachloroethane solution of diethyldiallyl malonate with $5 \mathrm{~mol} \%$ of catalyst 33e (activation), followed by 5 min heating at $80^{\circ} \mathrm{C}$ (deactivation). Thus, whilst heating may be initially perceived as counterintuitive, it may be used to regenerate the latent species instead of activating it.

\section{Indirect metathesis photoactivation}

An alternative approach for photoinitiated metathesis is indirect activation.

Grubbs et al. [79] demonstrated the use of photoacid generators (PAG) 34 and 35 (Figure 13) for the sub-300 nm UV activation of metathesis precatalysts $\mathbf{3 6}$ and $\mathbf{3 7}$ (Scheme 8). Thus, an acid sensitive olefin metathesis catalyst can be photoactivated by using a PAG in a tandem approach. Clearly, all other acids must be excluded from the reaction mixtures for the procedure to be effective.

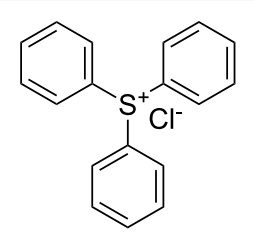

34

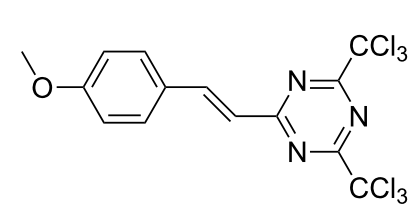

35
Figure 13: Photoacid generators for photoinduced metathesis.

Acid sensitive complexes $\mathbf{3 6}$ and $\mathbf{3 7}$ were synthesised starting from the Grubbs type catalysts $\mathbf{3 8}$ and $\mathbf{3 9}$ and thallium hexamethylacetylacetonate (Scheme 8). Several RCM substrates were closed as shown in Table 6 by the PAG induced metathesis. Complexes 36 or 37 and PAG 34 also polymerised typical ROMP monomers in excellent conversion (Table 7).

A dramatic loss of activity was observed when the chloride anion of PAG 31 was replaced by the non-nucleophilic nonaflate ion, implying that the chloride plays a crucial role in

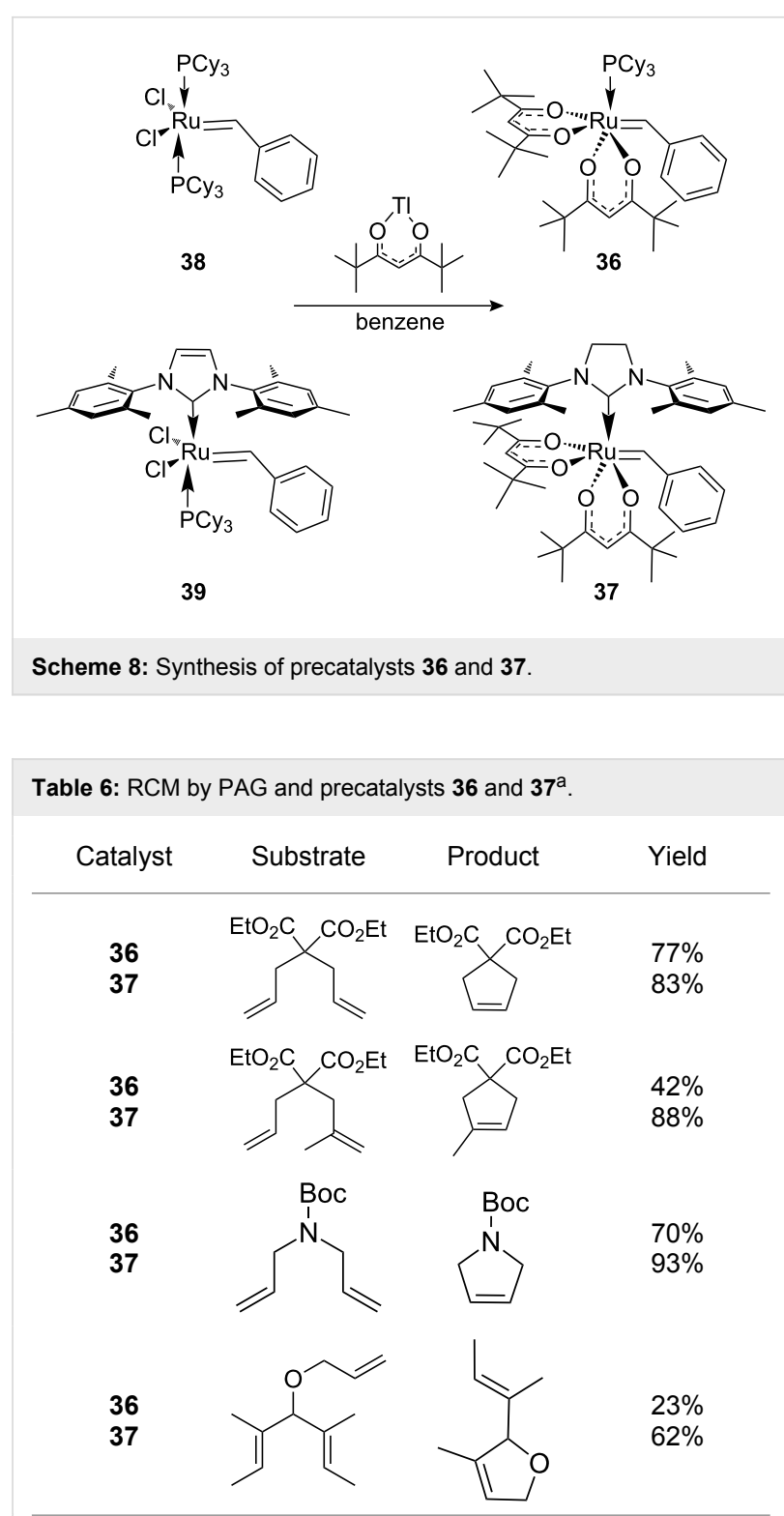

a $5 \mathrm{~mol} \%$ of $\mathbf{3 3 / 3 4}, 10 \mathrm{~mol} \%$ of $\mathbf{3 1}$ and substrate in a quartz NMR tube in $\mathrm{CD}_{2} \mathrm{Cl}_{2}(0.1 \mathrm{M})$; bisolated after column chromatography.

the photoactivation of this system. A cunning trapping experiment using the isopropoxy aromatic derivative $\mathbf{4 0}$ (Scheme 9) provided a better understanding of the activation mechanism and led to the proposal of the well-known 14-electron complex 41 as the actual active species.

Another excellent example for nondirect activation of metathesis is the light-triggerable liquid-filled solid microcapsules (MCs) presented by Fréchet et al. in 2009 [80]. A solution of 39 in toluene inside macrocapsules (Figure 14) can stand for weeks in neat DCPD without any appreciable reaction. However, near-IR laser bursting of the MCs causes gelling due to polymerisation within min. 
Table 7: ROMP by PAG and precatalysts 36 and $37^{\mathrm{a}}$.

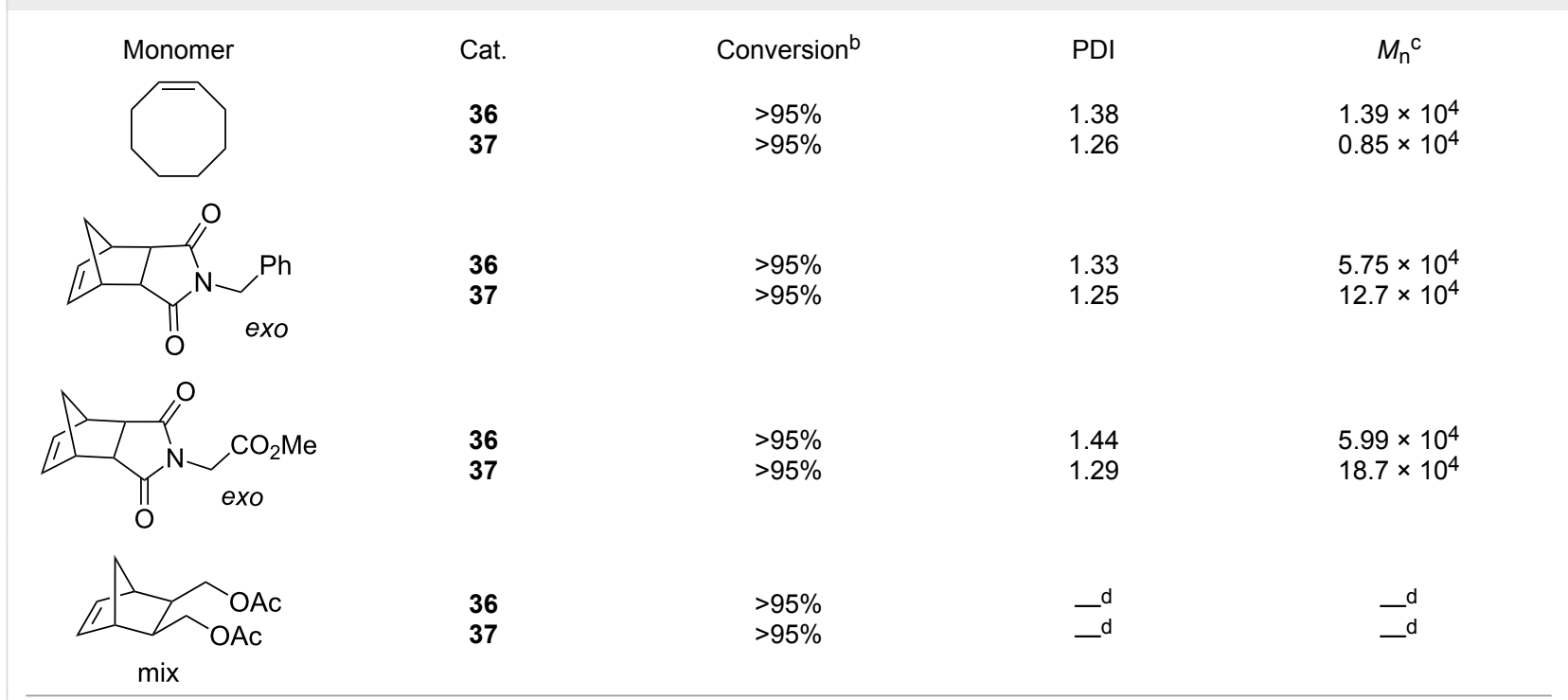

a36, $37(5 \mathrm{~mol} \%), 34(10 \mathrm{~mol} \%)$ and monomer $(0.1 \mathrm{M})$ in a quartz NMR tube with $\mathrm{CD}_{2} \mathrm{Cl}_{2} ;{ }^{\mathrm{b}}$ determined by ${ }^{1} \mathrm{H}$ NMR spectroscopy; ${ }^{\mathrm{c}}$ measured by MALLS-GPC; dinsolubility precluded GPC analysis.

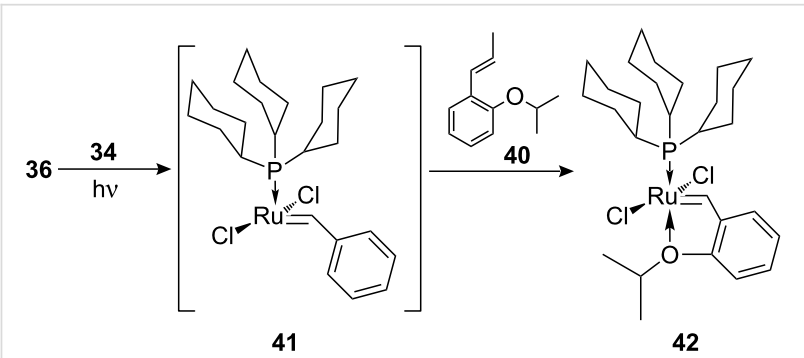

Scheme 9: Trapping of proposed intermediate 41.

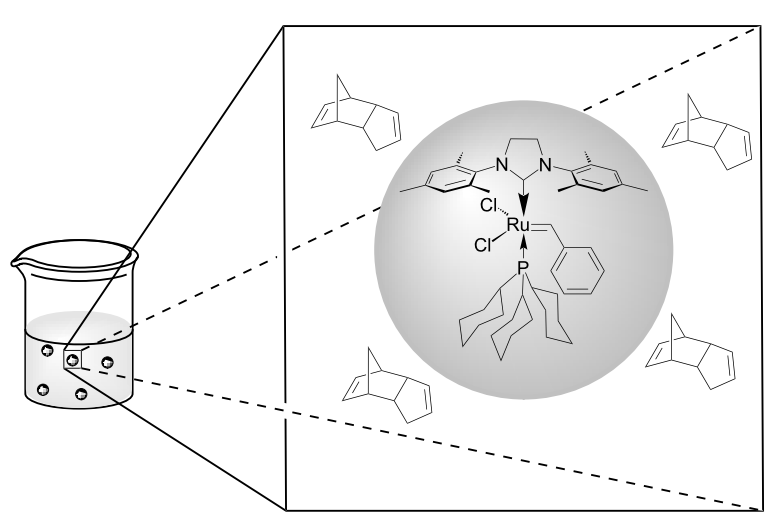

Figure 14: Encapsulated 39, isolated from the monomer.

\section{Conclusion}

Initially, the field of photoinduced olefin metathesis was mainly based on $\mathrm{W}(\mathrm{CO})_{6}$ chemistry. However, slowly over time functional group tolerant ruthenium applications emerged and these now dominate the field. Either by indirect or direct methods, the activation of ruthenium olefin metathesis catalysts may lead the way to novel applications in the areas of photolithography [81,82], roll-to-roll coating [69], 3D-printing, and self-healing [83] procedures in polymers. The use of photoswitchable catalysts may also have important safety advantages for industrial processes. As frequently seen in the successful field of olefin metathesis, the use of light to activate and direct these reactions certainly has a bright future ahead.

\section{References}

1. Hoveyda, A. H.; Zhugralin, A. R. Nature 2007, 450, 243-250. doi:10.1038/nature06351

2. Malcolmson, S. J.; Meek, S. J.; Sattely, E. S.; Schrock, R. R.; Hoveyda, A. H. Nature 2008, 456, 933-937. doi:10.1038/nature07594

3. Fürstner, A. Angew. Chem., Int. Ed. 2000, 39, 3012-3043. doi:10.1002/1521-3773(20000901)39:17<3012::AID-ANIE3012>3.0.CO ;2-G

4. Schrock, R. R.; Czekelius, C. Adv. Synth. Catal. 2007, 349, 55-77. doi:10.1002/adsc.200600459

5. Diesendruck, C. E.; Tzur, E.; Lemcoff, N. G. Eur. J. Inorg. Chem. 2009, 28, 4185-4203. doi:10.1002/ejic.200900526

6. Bieniek, M.; Michrowska, A.; Usanov, D. L.; Grela, K. Chem.-Eur. J. 2008, 14, 806-818. doi:10.1002/chem.200701340

7. Trnka, T. M.; Grubbs, R. H. Acc. Chem. Res. 2001, 34, 18-29. doi:10.1021/ar000114f

8. Lozano-Vila, A. M.; Monsaert, S.; Bajek, A.; Verpoort, F. Chem. Rev. 2010, 110, 4865-4909. doi:10.1021/cr900346r

9. Leitgeb, A.; Wappel, J.; Slugovc, C. Polymer 2010, 51, 2927-2946. doi:10.1016/j.polymer.2010.05.002

10. Bielawski, C. W.; Grubbs, R. H. Prog. Polym. Sci. 2007, 32, 1-29. doi:10.1016/j.progpolymsci.2006.08.006 
11. Grubbs, R. H., Ed. Handbook of Metathesis; Wiley-VCH: Weinheim, Germany, 2003; Vol. 3.

12. Mol, J. C. J. Mol. Catal. A 2004, 213, 39-45. doi:10.1016/j.molcata.2003.10.049

13. Baughman, T. W.; Wagener, K. B. Adv. Polym. Sci. 2005, 176, 1-42.

14. Hoveyda, A. H.; Malcolmson, S. J.; Meek, S. J.; Zhugralin, A. R. Angew. Chem., Int. Ed. 2010, 49, 34-44. doi:10.1002/anie.200904491

15. Reymond, S.; Ferrié, L.; Guérinot, A.; Capdevielle, P.; Cossy, J. Pure Appl. Chem. 2008, 80, 1683-1691. doi:10.1351/pac200880081683

16. Mori, M. Adv. Synth. Catal. 2007, 349, 121-135. doi:10.1002/adsc.200600484

17. Nicolaou, K. C.; Bulger, P. G.; Sarlah, D. Angew. Chem., Int. Ed. 2005, 44, 4490-4527. doi:10.1002/anie.200500369

18. Connon, S. J.; Blechert, S. Angew. Chem., Int. Ed. 2003, 42, 1900-1923. doi:10.1002/anie.200200556

19. Pozgan, F.; Dixneuf, P. H. Recent applications of alkene metathesis for fine chemical and supramolecular system synthesis.. In Metathesis Chemistry: From Nanostructure Design to Synthesis of Advanced Materials; Imamoglu, Y.; Dragutan, V., Eds.; NATO Science Series II: Mathematics, Physics and Chemistry, Vol. 243; Springer: Dordrecht, The Netherlands, 2007; pp 195-222.

20. Mele, G.; Li, J.; Vasapollo, G. Chim. Oggi 2008, 26, 72-74.

21. The Nobel Prize in Chemistry 2005, 5 Oct 2005, http://nobelprize.org.

22. Connon, S. J.; Blechert, S. Bioorg. Med. Chem. Lett. 2002, 12, 1873-1876. doi:10.1016/S0960-894X(02)00260-3

23. Gulajski, L.; Michrowska, A.; Bujok, R.; Grela, K. J. Mol. Catal. A 2006, 254, 118-123. doi:10.1016/j.molcata.2005.12.049

24. Jordan, J. P.; Grubbs, R. H. Angew. Chem., Int. Ed. 2007, 46, 5152-5155. doi:10.1002/anie.200701258

25. Michrowska, A.; Gulajski, L.; Kaczmarska, Z.; Mennecke, K.; Kirschning, A.; Grela, K. Green Chem. 2006, 8, 685-688. doi:10.1039/b605138c

26. Burtscher, D.; Grela, K. Angew. Chem., Int. Ed. 2009, 48, 442-454. doi:10.1002/anie.200801451

27. Giudici, R. E.; Hoveyda, A. H. J. Am. Chem. Soc. 2007, 129, 3824-3825. doi:10.1021/ja070187v

28. Keitz, B. K.; Grubbs, R. H. Organometallics 2010, 29, 403-408. doi:10.1021/om900864r

29. Stenne, B.; Timperio, J.; Savoie, J.; Dudding, T.; Collins, S. K. Org. Lett. 2010, 12, 2032-2035. doi:10.1021/ol100511d

30. Schmidt, B.; Staude, L. J. Org. Chem. 2009, 74, 9237-9240. doi:10.1021/jo9018649

31. Szadkowska, A.; Grela, K. Curr. Org. Chem. 2008, 12, 1631-1647. doi:10.2174/138527208786786264

32. Monsaert, S.; Ledoux, N.; Drozdzak, R.; Verpoort, F. J. Polym. Sci., Part A: Polym. Chem. 2010, 48, 302-310. doi:10.1002/pola.23784

33. Gstrein, X.; Burtscher, D.; Szadkowska, A.; Brabasiewicz, M.; Stelzer, F.; Grela, K.; Slugovc, C. J. Polym. Sci., Part A: Polym. Chem. 2007, 45, 3494-3500. doi:10.1002/pola.22083

34. Piermattei, A.; Karthikeyan, S.; Sijbesma, R. P. Nat. Chem. 2009, 1, 133-137. doi:10.1038/nchem.167

35. Stoll, R. S.; Hecht, S. Angew. Chem., Int. Ed. 2010, 49, 5054-5075.

36. Krausz, P.; Garnier, F.; Dubois, J.-E. J. Am. Chem. Soc. 1975, 97, 437-438. doi:10.1021/ja00835a044

37. Agapiou, A.; McNelis, E. J. Chem. Soc., Chem. Commun. 1975, 6, 187a. doi:10.1039/C3975000187A

38. Agapiou, A.; McNelis, E. J. Organomet. Chem. 1975, 99, C47-48. doi:10.1016/S0022-328X(00)86301-9
39. Krausz, P.; Garnier, F.; Dubois, J.-E. J. Organomet. Chem. 1976, 108, 197-202. doi:10.1016/S0022-328X(00)82140-3

40. Krausz, P.; Garnier, F.; Dubois, J.-E. J. Organomet. Chem. 1978, 146, 125-134. doi:10.1016/S0022-328X(00)91439-6

41. Garnier, F.; Krausz, P.; Dubois, J.-E. J. Organomet. Chem. 1979, 170 , 195-201. doi:10.1016/S0022-328X(00)81083-9

42. Garnier, F.; Krausz, P.; Rudler, H. J. Organomet. Chem. 1980, 186, 77-83. doi:10.1016/S0022-328X(00)93819-1

43. Tanielian, C.; Kieffer, R.; Harfouch, A. Tetrahedron Lett. 1977, 18, 4589-4592. doi:10.1016/S0040-4039(01)83576-0

44. Tanielian, C.; Kieffer, R.; Harfouch, A. J. Mol. Catal. 1981, 10, 269-284. doi:10.1016/0304-5102(81)85049-3

45. Nagasowa, M.; Kikukawa, K.; Takagi, M.; Matsuda, T. Bull. Chem. Soc. Jpn. 1978, 51, 1291-1293.

46. Borowczak, D.; Szymańska-Buzar, T.; Ziłkowski, J. J. J. Mol. Catal. 1984, 27, 355-365. doi:10.1016/0304-5102(84)85094-4

47. Szymańska-Buzar, T.; Ziłkowski, J. J. J. Mol. Catal. 1987, 43, 161-170. doi:10.1016/0304-5102(87)87003-7

48. Imamoglu, Y.; Zümreoglu, B.; Amass, A. J. J. Mol. Catal. 1986, 36, 107-114. doi:10.1016/0304-5102(86)85106-9

49. Szymańska-Buzar, T. J. Mol. Catal. 1988, 48, 43-57. doi:10.1016/0304-5102(88)85127-7

50. Schilder, P. G. M.; Stufkens, D. J.; Oskam, A.; Mol, J. C. J. Organomet. Chem. 1992, 426, 351-359. doi:10.1016/0022-328X(92)83068-S

51. Subbotina, I. R.; Shelimov, B. N.; Kazansky, V. B. Kinet. Catal. 1997, 38, 678-684.

52. Gita, B.; Sundararajan, G. Tetrahedron Lett. 1993, 34, 6123-6126. doi:10.1016/S0040-4039(00)61746-X

53. Gita, B.; Sundararajan, G. J. Mol. Catal. A 1997, 79, 79-84. doi:10.1016/S1381-1169(96)00085-4

54. Bhukta, G.; Manivannan, R.; Sundarajan, G. J. Organomet. Chem. 2000, 601, 16-21. doi:10.1016/S0022-328X(00)00015-2

55. Tamura, K.; Masuda, T.; Higashimura, T. Polym. Bull. 1994, 32, 289-296. doi:10.1007/BF00308539

56. Katz, T. J.; Ho, T. H.; Shih, N. Y.; Ying, Y. C.; Stuart, V. I. W. J. Am. Chem. Soc. 1984, 106, 2659-2668. doi:10.1021/ja00321a029

57. Katz, T. J.; Lee, S. J. J. Am. Chem. Soc. 1980, 102, 422-424. doi:10.1021/ja00521a094

58. Foley, H. C.; Strubinger, L. M.; Targos, T. S.; Geoffrey, G. L. J. Am. Chem. Soc. 1983, 105, 3064-3073. doi:10.1021/ja00348a020

59. Hafner, A.; Mühlebach, A.; van der Schaaf, P. Angew. Chem., Int. Ed. 1996, 35, 1845-1847. doi:10.1002/anie.199618451

60 . The term 'latency' may lead to some controversy. We define a catalyst as latent when no appreciable reaction is observed for a given time period (i.e., $24 \mathrm{~h}$ ) without an external stimulus (i.e., UV light) and noticeable product formation may be measured after the external stimulus is applied. See also reference [78].

61. Karlen, T.; Ludi, A.; Mühlebach, A.; Bernhard, P.; Pharisa, C. J. Polym. Sci., Part A: Polym. Chem. 1995, 33, 1665-1674. doi:10.1002/pola.1995.080331013

62. Hafner, A.; Mühlebach, A.; van der Schaaf, P. Angew. Chem., Int. Ed. 1997, 36, 2121-2124. doi:10.1002/anie.199721211

63. Hafner, A.; van der Schaaf, P.; Mühlebach, A.; Bernhard, P.; Schaedeli, U.; Karlen, T.; Ludi, A. Prog. Org. Coat. 1997, 32, 89-96. doi:10.1016/S0300-9440(97)00064-7

64. Fürstner, A.; Ackermann, L. Chem. Commun. 1999, 95-96. doi:10.1039/A808810A

65. Picquet, M.; Bruneau, C.; Dixneuf, P. H. Chem. Commun. 1998, 20, 2249-2250. doi:10.1039/A806005C 
66. Huang, J.; Stevens, E. D.; Nolan, S. P.; Petersen, J. L.

J. Am. Chem. Soc. 1999, 121, 2674-2678. doi:10.1021/ja9831352

67. Scholl, M.; Ding, S.; Lee, C. W.; Grubbs, R. H. Org. Lett. 1999, 1, 953-956. doi:10.1021/ol990909q

68. Delaude, L.; Demonceau, A.; Noels, A. F. Chem. Commun. 2001, 986-987. doi:10.1039/B101699G

69. Delaude, L.; Szypa, M.; Demonceau, A.; Noels, A. F. Adv. Synth. Catal. 2002, 344, 749-756. doi:10.1002/1615-4169(200208)344:6/7<749::AID-ADSC749>3.0.CO;2 $-\mathrm{T}$

70. Zhang, Y.; Wang, D.; Lönnecke, P.; Scherzer, T.; Buchmeiser, M. R. Macromol. Symp. 2006, 236, 30-37. doi:10.1002/masy.200690064

71. Wang, D.; Wurst, K.; Knolle, W.; Decker, U.; Prager, L.; Naumov, S.; Buchmeiser, M. R. Angew. Chem., Int. Ed. 2008, 47, 3267-3270. doi:10.1002/anie.200705220

72. Wang, D.; Decker, U.; Kühnel, C.; Buchmeiser, M. R. Polym. Prepr. 2010, 51, 384-385

73. Ben-Asuly, A.; Tzur, E.; Diesendruck, C. E.; Sigalov, M.; Goldberg, I.; Lemcoff, N. G. Organometallics 2008, 27, 811-813. doi:10.1021/om701180z

74. Kost, T.; Sigalov, M.; Goldberg, I.; Ben-Asuly, A.; Lemcoff, N. G. J. Organomet. Chem. 2008, 693, 2200-2203. doi:10.1016/j.jorganchem.2008.03.028

75. Diesendruck, C. E.; Vidavsky, Y.; Ben-Asuly, A.; Lemcoff, N. G. J. Polym. Sci., Part A: Polym. Chem. 2009, 47, 4209-4213. doi:10.1002/pola.23476

76. Diesendruck, C. E.; lliashevsky, O.; Ben-Asuly, A.; Goldberg, I.; Lemcoff, N. G. Macromol. Symp. 2010, 293, 33-38. doi:10.1002/masy.200900036

77. Tzur, E.; Szadkowska, A.; Ben-Asuly, A.; Makal, A.; Goldberg, I.; Wozniak, K.; Grela, K.; Lemcoff, N. G. Chem.-Eur. J. 2010, 16, 8726-8737. doi:10.1002/chem.200903457

78. Ben-Asuly, A.; Aharoni, A.; Diesendruck, C. E.; Vidavsky, Y.; Goldberg, I.; Straub, B. F.; Lemcoff, N. G. Organometallics 2009, 28, 4652-4655. doi:10.1021/om9004302

79. Keitz, B. K.; Grubbs, R. H. J. Am. Chem. Soc. 2009, 131, 2038-2039. doi:10.1021/ja807187u

80. Pastine, S. J.; Okawa, D.; Zettl, A.; Fréchet, J. M. J. J. Am. Chem. Soc. 2009, 131, 13586-13587. doi:10.1021/ja905378v

81. Ito, H.; Willson, C. G. Applications of Photoinitiators to the Design of Resists for Semiconductor Manufacturing. In Polymers in Electronics; Davidson, T., Ed.; ACS Symposium Series, Vol. 242; ACS Publications: Washington, U. S. A., 1984; pp 11-23. doi:10.1021/bk-1984-0242.ch002

82. Harris, R. F.; Ricci, M. J.; Farrer, R. A.; Praino, J.; Miller, S. J.; Saleh, B. E. A.; Teich, M. C.; Fourkas, J. T. Adv. Mater. 2005, 17, 39-42. doi:10.1002/adma.200400311

83. Toohey, K. S.; Sottos, N. R.; Lewis, J. A.; Moore, J. S.; White, S. R. Nat. Mater. 2007, 6, 581-585. doi:10.1038/nmat1934

\section{License and Terms}

This is an Open Access article under the terms of the Creative Commons Attribution License

(http://creativecommons.org/licenses/by/2.0), which permits unrestricted use, distribution, and reproduction in any medium, provided the original work is properly cited.

The license is subject to the Beilstein Journal of Organic Chemistry terms and conditions:

(http://www.beilstein-journals.org/bjoc)

The definitive version of this article is the electronic one which can be found at:

doi:10.3762/bjoc.6.127 